THE KURUME MEIICAL JOURNAL

Vol.27, p. 51-56, 1980

\title{
PRENATAL HYDROCORTISONE ADMINISTRATION AND LYMPHOCYTE RESPONSE IN THE NEONATAL RABBITS
}

\author{
M. MITSUO YOKOYAMA ${ }^{12}{ }^{2)}$, MADAN L. GUPTA ${ }^{2)}$, \\ DHARMATURI VIDYASAGAR ${ }^{2)}$ AND MEHRUNNISSA A. ZARIFF ${ }^{2)}$
}

Department of Immunology, Kurume University School of Medicine, Kurume, 830, Japan ${ }^{1}$ and Departments of Pediatrics and Pathology, University of Illinois College of Medicine Chicago, Illinois, U.S.A. ${ }^{2}$

Received for publication November 26, 1979

The influence of hydrocortisone to lymphocyte response against PHA stimulation was studied in neonatal rabbits. Prenatally, six pregnant rabbits were given hydrocortisone and seven control pregnant rabbits were given physiological saline at the 28th, 29th and 30th day of gestation. After delivery, lymphocytes of the neonates were tested within 48 hours.

The stimulation index after the lymphocytes were cultered with PHA of $1: 100$ was $11.15 \pm 2.14$ in saline-treated control, versus $2.43 \pm 1.0$ in the steroid-treated group $(p<0.005)$. Similar difference in S.I. was also found with PHA $1: 1000,9.56 \pm 2.84$ in saline versus $1.54 \pm 0.13$ in the steroid group $(\mathrm{p}<0.02)$.

Postnatally, neonates were divided into two groups, one was given hydrocortisone, the other saline on the 1st, 2nd and 3rd day of age. The neonates were sacrificed at $72-120$ hours of age and the blood collected for lymphocyte studies.

The stimulation index in the treatment neonates with PHA was significantly depressed in the steroid-treated group when the results were compared with the control group. Steroid when administered prenatally or postnatally, suppresses lymphocyte function in the neonatal rabbits.

\section{INTRODUCTION}

Corticosteroids have widely been used in the treatment of inflammatory conditions (Skinner and Schwartz, 1974) and also as an immunosuppresive agent, notably in the transplantation (Koutz, 1973). The inhibitory effect of corticosteroids upon lymphocyte response in vivo has been known since Dougherty (1953) reported in 1952. To dermine the effect of drugs to immune system test for lymphocyte responsiveness to mitogens, in vitro has commonly been used as an immunological monitoring and the drugs were found to be suppress lymphocyte activation (Nowell, 1961).
The administration of corticosteroids to fetuses in experimental animals were found to be an accelerated maturation of pulmonary surfactant (De Lemos et al., 1970 ; De Lemos and Mc Laughlin, 1973 ; Motoyama et al., 1971). There is a great concern regarding the adverse effects of the corticosteroids on the growing fetus. Treatment of infant rats with a single injection of methylprednisone resulted in alterations in myelination with the immaturation of the brain and the normal increase in cell number was severely inhibited during the period of cortisol treatment (Cohen, 1972 ; Cotterrel et al., 1972 ; Cumbinas et al., 1973). Suppression of 
thymic function following postnatal steroid therapy has been reported. Intravascular injection of methylprednisone is found to prolong the average survival of the grafts in rabbits and human (Coburg et al., 1970). Furthermore, corticosteroid administration in man has been demonstrated to cause a transient depletion of lymphocytes, predominately in the thymus-derived (T) cell population (Fanci and Dale, 1974). The purpose of this study was to investigate the effect of prenatal administration of corticosteroids on the immune system as a lymphocyte function in the rabbit neonates, and the results were compared with the effect on postnatal rabbits.

\section{MATERIALS AND METHODS}

The response of lymphocytes to PHA stimulation was used to assess function in two groups of neonatal rabbits : one prenatally-treated and the other postnatally-treated.

\section{Prenatal Study:}

Thirteen pregnant albino New Zealand rabbits with timed mating were used. Six were treated with hydrocortisone sodium succinate (Solucorted, Upjohn Co., Kalamazoo, Michigan) 10 $\mathrm{mg} / \mathrm{kg}$. $(0.5 \mathrm{ml})$ and seven with $0.5 \mathrm{ml}$ of normal saline at $28 \mathrm{th}, 29 \mathrm{th}$ and $30 \mathrm{th}$ days of gestation, and they were allowed to deliver spontaneously.

Blood for lymphocyte studies was collected in heparinized tubes within 48 hours of age. Because of the small quanitity of blood obtained from each newborn, blood from all neonates in the litter was pooled for the study.

\section{Postnatal Study:}

Seven litters born to pregnant rabbits after term gestation were used.
Half of the neonates in the litter were given hydrocortisone $20 \mathrm{mg} / \mathrm{kg}$, and the remaining neonates were injected with $0.5 \mathrm{ml}$ saline subcutaneously at 1,2 and 3 days of age. Neonates were sacrificed at $72-120$ hours of age and blood collected in heparinized tubes by decapitation. All the seven neonates receiving steroid were included in the study.

\section{Preparation and Culture of Lymphocyte} Suspension :

Mononuclear cells were obtained by Hypaque-Ficoll density gradient centrifugation (Boyum, 1968). The cells were washed twice in RPMI media (RPMI1640 with glutamine without antibiotic, Grand Island Biological Company (GIBCO), Grand Island, N. Y. 14072) and suspended in RPMI media containing $10 \%$ fetal calf serum (GIBCO), $100 \mu / \mathrm{ml}$ of penicillin (E. R. Squibb and Sons Inc., Princeton, N. J. ) and $100 \mu \mathrm{g} / \mathrm{ml}$ of streptomycin sulphate (Pfizer Laboratories Division, New York). Cultures were done in microtiter plates (Cook Laboratory Products, Cook Laboratory Products, Cook Engineering Co., Alexandria, VA.). Each well contained 0.1 $\mathrm{ml}$ of cells in a concentration of $1 \times 10^{6}$ lymphocytes $/ \mathrm{ml}$ and $0.1 \mathrm{ml}$ of either RPMI media with fetal calf serum of mitogens in different concentrations. Phytohemagglutinin (PHA, MR68, Lot K 4402, The Wellcome Research Laboratories, Beckenham, Kent, England) in concentration of $1: 100$ and $1: 1000$ was used as a mitogenic stimulant. Triple cultures were incubated at $37^{\circ} \mathrm{C}$ in $5 \%$ $\mathrm{CO}_{2}$ in air, and $100 \%$ humidity for 72 hours. Four hours before harvesting, $0.4 \mu \mathrm{ci}$ of tritiated thymidine $(6.7 \mu \mathrm{ci} /$ $\mathrm{mN}$, New England Nuclear, Boston, Mass. ) was added to each well. The cells were collected from the wells onto a glass fiber filter (Grade $93 \mathrm{AH}$ Reeve Angel, Lot No. 5016, Whatman Inc., 
Dedham, Mass., CHAP 100) and placed in $10 \mathrm{ml}$ of aquasol (New England $\mathrm{Nu}$ clear). Radioactivity was measured in a liquid scintillation counter (Packard Tri-Carb Liquid Scintillation Spectrometer, Model 3003). The arithmetric mean of counts per minute (cpm) of triplate cultures was determined and stimulation index (S.I.) was expressed as a ratio of count per minute in stimulated and unstimulated cultures. Stimulation index was compared between the control and steroid group. 'The student t-test was used to measure the statistical significance.

\section{RESULTS}

In Table I, data of the prenatallytreated neonates is shown. The mean age at study in saline treated group and steroid group was two days. The S.I. when cultured with PHA of $1: 100$ dilution was $11.15 \pm 2.14$ in saline-treated, versus $2.43 \pm 1.0$ in the steroid-treated group. There was a significant difference between the two groups $(p<$ 0.005). Similar difference in stimulation index was found with PHA $1: 1000$ dilution, $9.56 \pm 2.84$ in saline versus 1.54 \pm 0.13 in steroid group, $\mathrm{p}<0.02$.

TABLE 1

Results of lymphocyte stimulation with and without PHA comparing between prenatal control and steroid-treated groups

Prenatal Control Group

\begin{tabular}{|c|c|c|c|c|c|c|}
\hline No. Rabbit & $\begin{array}{c}\text { Age at Expt. } \\
\text { (hours) }\end{array}$ & (Unstimulated) & $\begin{array}{c}\text { CPM } \\
(\text { PHA1 : 100) }\end{array}$ & S. I. & $\begin{array}{c}\text { CPM } \\
(\text { PHA1 }: 1000)\end{array}$ & S. I. \\
\hline 1 & 96 & 1694.4 & 9033.8 & 5.33 & 6046.5 & 3.56 \\
\hline 2 & 23 & 1944.0 & 5873. 7 & 3. 02 & 5556.4 & 2.83 \\
\hline 3 & 1 & 88.4 & 1365.6 & 15.44 & 1163.6 & 13. 15 \\
\hline 4 & 48 & 119.4 & 1639.2 & 13. 74 & 558.6 & 4.68 \\
\hline 5 & 48 & 21.8 & 350.6 & 15.90 & 288.3 & 13.22 \\
\hline 6 & 48 & 18.6 & 313.6 & 16.83 & 437.9 & 23.50 \\
\hline 7 & 48 & 28.8 & 225.1 & 7.82 & 225.1 & 6. 02 \\
\hline Mean & 44.6 & 559. 37 & 2685.92 & 11.15 & 2039.5 & 9.56 \\
\hline \pm S.D. & \pm 10.9 & \pm 326.7 & \pm 1200.68 & \pm 2.14 & \pm 981.79 & \pm 2.84 \\
\hline
\end{tabular}

Prenatally Steroid-Treated Group

\begin{tabular}{c|cc|c|ccc} 
No. Rabbit & $\begin{array}{c}\text { Age at Expt. } \\
\text { (hours) }\end{array}$ & $\begin{array}{c}\text { CPM } \\
\text { (Unstimulated) }\end{array}$ & $\begin{array}{c}\text { CPM } \\
(\text { PHA1 }: 100)\end{array}$ & S. I. & $\begin{array}{c}\text { CPM } \\
(\text { PHA1:1000) }\end{array}$ & S. I. \\
\hline 1 & 48 & 251.7 & 574.4 & 2.28 & 285.5 & 1.13 \\
2 & 48 & 437.5 & 437.5 & 0.88 & 643.0 & 1.30 \\
3 & 48 & 7275.4 & 13490.1 & 1.85 & 10338.6 & 1.42 \\
4 & 48 & 27.0 & 31.3 & 1.16 & 37.0 & 1.37 \\
5 & 48 & 441.9 & 3371.1 & 7.62 & 1209.0 & 2.73 \\
6 & 48 & 420.0 & 356.8 & 0.86 & 553.0 & 1.29 \\
\hline Mean & 48 & 1484.61 & 3043.58 & 2.43 & 1015.12 & 1.54 \\
\pm S.D. & & \pm 1164.7 & \pm 2156.34 & \pm 1.06 & \pm 536.0 & \pm 0.13
\end{tabular}


TABLE 2

Comparison of lymphocyte stimulation between control and steroid-treated groups with and without PHA

\begin{tabular}{|c|c|c|c|c|c|c|}
\hline \multirow[b]{2}{*}{ No. Rabbit } & \multicolumn{6}{|c|}{ Postnatal Control Group } \\
\hline & $\begin{array}{l}\text { Age at Expt. } \\
\text { (hours) }\end{array}$ & $\mid \begin{array}{c}\text { CPM } \\
\text { (Unstimulated) }\end{array}$ & $\begin{array}{c}\text { CPM } \\
(\mathrm{PHA1}: 100)\end{array}$ & S.I. & $\begin{array}{c}\text { CPM } \\
(\text { PHA1 }: 1000)\end{array}$ & S. I. \\
\hline 1 & 96 & 14.0 & 20.9 & 1.48 & 23.67 & 1.68 \\
\hline 2 & 96 & 19.1 & 105.3 & 5.54 & 179.26 & 9.43 \\
\hline 3 & 96 & 21.5 & 55.6 & 2.58 & 34.18 & 1.59 \\
\hline 4 & 120 & 34.8 & 483.3 & 13.80 & 412.20 & 11.80 \\
\hline 5 & 96 & 42.5 & 164.7 & 3.87 & 343.05 & 8. 10 \\
\hline \multirow{3}{*}{$\begin{array}{l}\text { Mean } \\
\pm \text { S.D. }\end{array}$} & 100.8 & 26.44 & 165.9 & 5.45 & 198.47 & 6.52 \\
\hline & \pm 4.79 & \pm 5.29 & \pm 83.17 & \pm 2.19 & \pm 79.11 & \pm 2.15 \\
\hline & \multicolumn{6}{|c|}{ Postnatally Steroid-Treated Group } \\
\hline No. Rabbit & $\begin{array}{c}\text { Age at Expt. } \\
\text { (hours) }\end{array}$ & $\begin{array}{c}\mathrm{CPM} \\
\text { (Unstimulated) }\end{array}$ & $\begin{array}{c}\text { CPM } \\
(\mathrm{PHA} 1: 100)\end{array}$ & S.I. & $\mid \begin{array}{c}\text { CPM } \\
(\text { PHA1 }: 1000)\end{array}$ & S.I. \\
\hline 1 & 120 & 120.2 & 97.6 & 0.81 & 52.3 & 0.43 \\
\hline 2 & 72 & 23.3 & 36.6 & 1.57 & 12.3 & 0.52 \\
\hline 3 & 96 & 69.2 & 86.6 & 1.25 & 57.5 & 0.83 \\
\hline 4 & 96 & 32.4 & 25.4 & 0.78 & 23.5 & 0.72 \\
\hline 5 & 96 & 11.2 & 26.2 & 2.34 & 14.1 & 1.26 \\
\hline 6 & 96 & 17.0 & 12.2 & 0.71 & 25.3 & 1.48 \\
\hline 7 & 96 & 21.3 & 20.7 & 0.96 & 81.2 & 3. 79 \\
\hline Mean & 99.42 & 42.1 & 43.64 & 1.20 & 38.1 & 1.29 \\
\hline \pm S. D. & \pm 6.27 & \pm 14.9 & \pm 12.90 & \pm 0.22 & \pm 9.84 & \pm 0.43 \\
\hline
\end{tabular}

TABLE 3

Statistical analysis of stimulation index between control and steroid-treated groups

\begin{tabular}{|c|c|c|c|}
\hline Prenatal & $\begin{array}{c}\text { Saline-treated } \\
\text { Mean } \pm \text { S. D. }\end{array}$ & $\begin{array}{c}\text { Steroid-treated } \\
\text { Mean } \pm \text { S. D. }\end{array}$ & $\mathrm{p}$ \\
\hline PHA (1: 100) & $11.15 \pm 2.14$ & $2.43 \pm 1.06$ & $<0.005$ \\
\hline PHA $(1: 1000)$ & $9.56 \pm 2.84$ & $1.54 \pm 0.13$ & $<0.02$ \\
\hline $\mathrm{p}$ & n.s. & n.s. & \\
\hline Postnatal & $\begin{array}{c}\text { Saline-treated } \\
\text { Mean } \pm \text { S. D. }\end{array}$ & $\begin{array}{c}\text { Steroid-treated } \\
\text { Mean } \pm \text { S. D. }\end{array}$ & $\mathrm{p}$ \\
\hline PHA $(1: 100)$ & $5.45 \pm 2.19$ & $1.20 \pm 0.22$ & $<0.05$ \\
\hline P HA $(1: 1000)$ & $6.52 \pm 2.19$ & $1.20 \pm 0.22$ & $<0.05$ \\
\hline $\mathrm{p}$ & n.s. & n. s. & \\
\hline
\end{tabular}


The data of postnatally treated neonates is shown in Table II. In both groups, the studies were conducted around 4 days of postnatal age. The S.I. both with PHA $(1: 100)$ and PHA $(1: 1000)$ was significantly depressed in the steroid group, $\mathrm{p}<0.005$. Table III shows the summary of the results in both prenatal and postnatal groups.

\section{DISCUSSION}

There is convincing evidence of the beneficial effect of prenatal steroid administraion in accelerating the lung maturation (De Lemos, et al., 1970 ; De Lemos and Mc Laughlin, 1973; Motoyama, et al., 1971). However, there is a controversy regarding the side effects of such treatment of the fetus and the neonate. In animals, decreased fetal cellular growth of lungs, brain and thymus have been reported following corticosteroid therapy on the fetus (Carson, et al., 1973 ; Cohen, 1972 ; Cotterrel, et al., 1972 ; Cumbinas, et al., 1973 ; De Souza and Adlard, 1973). Corticosteroid therapy is also known to have a number of immunosuppressive effects such as : decreased antibody production (Butler and Rossen, 1973; Greenberg and Dimitrov, 1976), lymphopenia (Boyum, 1968; Esteban, 1968; Fauci, 1976) and suppression of cutaneous delayed hypersensitivity (Bovorknitti et al., 1960). Fauci (1976) has demonstrated temporary lymphopenia and decreased response of human lymphocytes to $\mathrm{mi}$ togen even with a single dose of hydrocortisone. Furthermore, in vitro studies, inhibition of mitogenesis was seen following the addition of corticosteroid to lymphocy te culture (Yu, et al., 1974). These findings indicate the need for study of effects on corticosteroid therapy on the immune response of the fetus. Fitzharding et al. (1974), re- ported normal immunocompetence at one year of age in infants who received corticosteroid at 24 hours of age. No such data is available in infants who received steroid therapy prenatally. In this study, stimulation of lymphocyte with PHA as an index of lymphocyte function was studied in both prenatally and postnatally treated neonatal rabbits. In steroid treated group, stimulation index was significantly impaired. Prenatal or postnatal administration did not show statistical difference in impairment. It should be noted that the steroid dose in the postnatal group was twice as much as the dose administered prenatally, which explains the apparent increased suppression of stimulation in the postnatal group (1.20 versus 2.43 at the dilution of PHA 1 : 100). The stimulation index between the prenatal and postnatal saline group showed no statistical difference although there was a trend towards the decreased mitogenic response in the postnatal group. We speculate that the stress of injection in the postnatal group itself may have played a role in this impairment.

This study demonstrated that steroid when administered prenatally or postnatally, suppresses lymphocyte function in the rabbit neonate. Persistence of immunosuppressive effect after administration of corticosteroid in the neonate needs a further study, but these findings could be of great significance in a preterm human neonate in whom administration of corticosteroids will suppress further, the already impaired cellular immunity.

\section{REFERENCES}

Bovorknitti, S., Kangsadal, P., Sathirapat, P. and Oonsombatti, P. (1960). Reversion and recoversion rate of tuberculin skin re- 
action in correlation with the use of prednisone. Dis. Chest., 35, 51.

Böyum, A. (1968). Separation of leukocyte from blood and bone marrow. Scand. J. Clin. Lab. Invest., 21, (suppl. 97), 1.

Butler, W. T. and Rossen, R. D. (1973). Effect of methylprednisone on immunoglobulin metabolism in man. Fed. Proc., 32, 1028.

Carson, S. H., Taeusch, Jr., H. W. and Avery, M. E. (1973). Inhibition of lung cell division after hydrocortisone injection into fetal rabbits. J. Appl. Physiol, 34, 660.

Coburg, A. J., Gray, S. H., Katz, F. H., Penn, I., Halgrimson, C. and Starzel, T. E. (1970). Disappearance rates and immunosuppression of intermittent intravenously administered prednisone in rabbits and human beings. Surg. Gynecol. Obst., 131, 933.

Cohen, J. J. (1972). Thymus derived lymphocyte sequested in the bone marrow of hydrocortisone-treated mice. J. Immunol., 108, 841.

Cotterrel, M., Balazs, R. and Johnson, A. L. (1972). Effects of corticosteroids on the biochemical maturation of rat brain : Postnatal cell formation. J. Neuro. Chem., 19, 2151.

Cumbinas, M., Oda, M. and Huttenlocker, P. (1973). The effects of corticosteroid on myelination of the developing rat brain. Biol. Neonate, 22, 355.

de Lemos, R. A., Shermeta, D. W. Knelson, J. H., Kotas, R. and Avery, M. E. (1970). Acceleration of appearnce of pulmonary surfactant in the fetal lamb by administration of corticosteroids. Amer. Rev. Resp. Dis., $102,459$.

De Lemos, R. A. and McLaughlin, G. W. (1973). Induction of pulmonary surfactant in fetal primate by the intrauterine administration of corticosteroids. Pediat. Res., 7, 425.

DesouzA, S. W. and Adlard, B. P. F. (1973). Growth of suckling rats after treatment with dexamethasone or cortisol. Implication for steroid therapy in human infants.
Arch. Dis. Child., 48, 519.

Dougherty, T. F. (1953). Effect of hormones on lymphatic tissue. Phisiol. Rev., 32, 379.

Esteban, J. N. (1968). The differential effect of hydrocortisone on the short lived small lymphocyte. Anat. Rec., 162, 349.

FAuci, A.S. and DAle,D.C. (1974). The effect of in vivo hydrocortisone on subpopulations of human lymphocytes. J. Clin. Invest., $53,240$.

FAuci, A. S. (1976). Mechanism of corticosteroid action on lymphocyte subpopulations. Differential effects of in vivo hydrocortisone. Prednisone and dexamethasone on in vitro expression lymphocyte function. Clin. Exp. Immunol., 24, 54.

Fitzhardinge, P. M., Eisen, A., Lejtenyi, C., Metrakos, K. and Ramsay, M. Sc. (1974). Sequelae of early steroid administration of the newborn infant. Pediat. 53, 877.

GreenberG, C. S. and Dimitrov, N. V. (1976). The effect of hydrocortisone on the immune response of mice treated with corynebacterium parvum. Clin. Immunol. Immunopath., 5, 264.

Koutz, S. L. (1973). Clinical transplantationan overview. Transplant. Proc., 5, 59.

Motoyama, E. K., Orzalesi, M. M., KikKawa, Y., Kaibara, M. M., Wu, B., Zigas, C. J. and Cook, C. D. (1971). The effects or cortisol in the maturation of fetal rabbit lungs. Pediat., 48, 547.

Nowell, P. C. (1961). Inhibition of human leukocyte mitosis by prednisone in vitro. Cancer Rev., 21, 1518.

Skinner, M. D. and Schwartz, R. S. (1974). Immunosuppressive therapy of immunoinflammatory disease. In Rheumatology, Ed. J. Rotstein, Karger, Basel, Vol. 4, p. 1.

Yu, D. T. Y., Clements, P. J., Paulus, H. E. Peter, J. B., Levy, J. and Barnett, E. V. (1974). Human lymphocyte subpopulations. Effect of corticosteroid. J. Clin. Invest., 53,565 . 